\title{
Is old stuff back? A fatal case of ethyl chloride sniffing
}

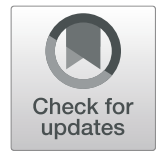

\author{
Jennifer P. Pascali ${ }^{1 *}$ D, Paolo Fais ${ }^{2}$, Guido Viel ${ }^{3}$, Giovanni Cecchetto ${ }^{3}$ and Massimo Montisci ${ }^{3}$
}

\begin{abstract}
Background: Ethyl chloride (EC) or chloroethane is a colourless halogenated hydrocarbon gas regularly employed as a topical anaesthetic spray for pain-related injuries and muscle spasm in athletes. However, EC became also popular as a street drug in the 1980s. Brief inhalations of EC vapour can result in dizziness, euphoria, confusion, incoordination, hallucinosis, impairment of short-term memory and narcosis. Inhalation of higher doses, usually employed to "get high", may be related to severe depression of the central nervous system. Indeed, toxicity and deaths have been reported so far.

Case presentation: A 40-year-old man was found unresponsive after EC inhalation. EC determination was performed by dynamic headspace gas chromatography coupled to mass spectrometry. EC was detected in the peripheral blood (0.156 $\mathrm{g} / \mathrm{L})$, central blood concentration $(0.203 \mathrm{~g} / \mathrm{L}$ ) and the lung and brain $(19$ and $25 \mathrm{mg} / \mathrm{kg}$ ). EC in the vitreous humour showed a sensitively lower respect to blood (0.018 vs $0.203 \mathrm{~g} / \mathrm{L}$ ).

Conclusions: Considering the results of toxicological analyses of investigations on the death scene besides the absence of any signs of trauma, death was attributed to inhalation of ethyl chloride.
\end{abstract}

Keywords: Forensic science, Forensic toxicology, Ethyl chloride, Chloroethane, Sudden sniffing deaths, Gas chromatography

\section{Background}

Ethyl chloride (EC) or chloroethane is a flammable gas (b.p. $12^{\circ} \mathrm{C}$ ) with a strong ether-like odour that has been used as a refrigerant, solvent and chemical intermediate. Originally, it was proposed as a general anaesthetic, filling the gap between the weaker narcotic nitrous oxide and the more powerful drugs ether and chloroform, but too much after-effects were reported (McCardie 1905). Nowadays, it is employed therapeutically as a topical anaesthetic spray for the control of pain in athletic injuries and muscle spasm. Moreover, EC finds application into the piercing/ tattoo industry to cool the skin down in order to limit pain related to piercing or tattoo procedures (Torfaen County Borough, Code of practice Body Piercing n.d.). This compound had been used as a recreational popular street drug in 1980s, but recently, its engagement as inhalant drug in recreative sniffing to "get high" is gaining renewed popularity among young people also in light to its wide availability (Ethyl Chloride, or EC, is new off-the-shelf high n.d.;

\footnotetext{
* Correspondence: jennifer.pascali@gmail.com

${ }^{1}$ Forensic Toxicology Division, Department of Health Sciences, University of Florence, Largo Brambilla 3, 50134 Florence, Italy

Full list of author information is available at the end of the article
}

Youths warned off sniffing 'deadly' new legal high Ethyl Chloride n.d.). For decades, volatile substances have been the least studied of misused substances because of low perception of social and health risks, high variability among products, and lack of attention in national and international research. These substances are highly volatile and are usually inhaled through nose and mouth, reaching rapidly the bloodstream and central nervous system. The type and pattern of substances abused vary. Among the volatile substances are aromatic hydrocarbons (e.g. toluene), halogenated compounds (e.g. ethyl chloride), ethers (e.g. diethyl ether), ketones (e.g. acetone) and alcohols. Inhalants produce different effects, temporary or permanent, depending on the chemical constituents, individual susceptibility, substance concentration and duration of exposure. Among volatiles, common effects include irritation of respiratory airways, impaired judgement, tremors, unsteady gait, blurred vision and memory impairment. Very high concentrations can produce anaesthesia, unconsciousness and even death (Cruz 2011). Deaths occurring after drug inhalation are collectively defined "sudden sniffing deaths" and have been reported after recreational butane (Kramp et al. 
2018), trichloroethylene (Da Broi et al. 2015) and butanepropane gas mixture (Romolo et al. 2017) inhalation.

$\mathrm{EC}$ is a volatile misused for recreational purposes. Cold liquid EC is usually sprayed into a towel or piece of cloth ad evaporating fumes are inhaled through the nose and the mouth. Inhaled EC vapour is rapidly excreted by the lungs and breath out; however, because of its high solubility, part of EC remains in the blood and total elimination from the body takes some time (Murray Lawson 1965). Effects of EC exposure result in dizziness, euphoria, confusion, incoordination, hallucinosis, impairment of short-term memory and narcosis also for brief exposures at high concentrations (Baselt 2014). Toxicological effects on humans were mostly studied from cases of occupational medicine, where EC is known to produce central nervous system depression at 40 , $000 \mathrm{ppm}(105.6 \mathrm{mg} / \mathrm{L})$ and weak analgesia after $12 \mathrm{~min}$ at 19,000 ppm (50.4 mg/L) (Clayton and Clayton 1993-1994). Acute mortality generally does not occur at exposure below 50,000 ppm (Tomei Torres and Keith 2016; Winek et al. 2001). Chronic EC abuse has been also related to long-term severe neurological impairment, including hallucinations and ataxia. In particular, these latter effects have been reported in a subject inhaling EC two to three times per week over a 4-month period (IARC 1991). Other studies reported impairment of liver function and leukocyte phagocytosis in chronic EC abusers, while animal studies demonstrated fetotoxic and carcinogenic effects (Kuthiah and Er 2019). Although the pharmacokinetics of EC in human has not been investigated, experimental studies on mice confirm that EC is oxidatively dechlorinated in an NADPH- and $\mathrm{O}_{2}$-dependent reaction and P450-dependent metabolism, resulting in the formation of acetaldehyde (Fedtke et al. 1994a) or conjugated with glutathione (GSH) in a reaction catalysed by GSHS-transferases (Fedtke et al. 1994b). Disregarding data from occupational exposure, which may represent situations far from illicit uses, forensic cases reporting EC concentrations on blood and tissues after recreational use are scarce in the literature. Indeed, very few old cases have been reported so far (Broussard et al. 2000; Yacoub et al. 1993), hampering the forensic toxicologist in the diagnosis of EC intoxication. Recently, cases of acute reversible neurologic deficits on young adults due to voluntarily EC sniffing were studied (Al-Ajmi et al. 2018; Senussi and Chalise 2015), although blood concentration values were not reported. Literature about fatal EC inhalation is scant and the most recent case reporting data on post-mortem tissue distribution is dated back almost 20 years ago (Broussard et al. 2000). The paucity of toxicological data on this rare cause of death limit the forensic toxicologist interpretation and identification of fatal EC intoxications.

On these grounds, we describe a case of fatal intoxication due to EC sniffing, providing medico-legal considerations and toxicological findings on different tissues, contributing to the casuistic over the inhalant intoxications, which determination may be difficult if some precautions on sample collection and storage at the crime scene are missing.

\section{Case presentation}

A 40-year-old white male (height $178 \mathrm{~cm}$, weight $71 \mathrm{~kg}$, body mass index 22.4) was found dead in his bedroom. The entire flat was in order, with no signs of violence and all the premises closed. Leftovers from a meal were found in the kitchen. No suicide notes were found. The corpse held a rag loosely on his mouth. Four cans (two empty, two partially empty) containing EC and labelled as cryo-anaesthetic were found next to the body. Two more empty cans containing ethyl chloride were found in the trash basket in the bedroom. The cans and the rag were collected from the scene, and a fragment from the rag was cut and stored in a sealed $20 \mathrm{~mL}$ headspace vial. The body displayed no signs of trauma, and onsite samples of the blood and vitreous humour were collected and stored in sealed headspace vials as well. All samples were kept refrigerated $\left(4^{\circ} \mathrm{C}\right)$ until analysis. An autopsy was performed the day after, and tissues from the brain and lung were also collected besides samples of central and peripheral blood.

\section{Toxicological analysis}

Ethyl chloride determination was performed by dynamic headspace gas chromatography coupled to mass spectrometry (GC-MS) coupled to thermal desorption extractor. Analytical parameters were from the method described in Kim et al. (2018). Sample preparation consisted of the addition of $7 \mathrm{~g}$ sodium sulphate to $2 \mathrm{~mL}$ or $2 \mathrm{~g}$ of biological material placed in a $20-\mathrm{mL}$ headspace. Single ion monitoring (SIM) acquisition mode was used for ions $\mathrm{m} / \mathrm{z}$ 64, 49 and 28 . Quantitation was done by external standard calibration. Samples were analysed in duplicate. Blood alcohol determination was performed by headspace gas chromatography coupled to flame ionization detector (HS-GC-FID) according to the method routinely used in the lab (sensitivity, expressed as limit of quantification $0.01 \mathrm{~g} / \mathrm{L}$ ). Traditional drugs of abuse (cocaine, morphine, codeine, cannabinoids, amphetamines/methamphetamines, ketamine and methadone) were searched by GC-MS on the blood (Bertol et al. 2018). Benzodiazepine and tricyclic antidepressant determination in the blood was performed by liquid chromatography coupled to tandem mass spectrometry (LC-MS/MS) following the method reported in Zhang et al. (2018).

\section{Results}

A forensic autopsy was performed one day later. Cadaveric dissection revealed nonspecific findings, such as slightly poly-visceral congestion, more evident in the brain and lungs. The coronaries and the myocardium were normal; white bubbly fluid in the bronchi and the parenchyma was detected. Integrating circumstantial data, including text messages on his smartphone with 
results of livor mortis, rigor mortis and rectal temperature evaluation, the post-mortem interval was determined between 12 and $24 \mathrm{~h}$ before inspection at the death scene. Anatomical sites for gaseous exposure sampling were suggested by the paper of Varlet et al. (2019) who very recently dealt with the forensic challenge of determining another anoxiant used for recreational sniffing, helium (He), in tissue samples. Helium, indeed, has been recognised as fatal anoxiant in recreative sniffing as well as in suicides, but ascribing the cause of death to this gas presented interpretative issues, if no circumstantial data (i.e. plastic bag) were retrieved. In fact, due to the He's very low affinity for biological samples, He diffusion easily occurs from the body. For this reason, the selection of sampling sites is of utmost importance in order to maximize the chances to highlight He presence in fatal cases. Varlet and colleagues investigated a number of cases of $\mathrm{He}$ intoxication, revealing the lung lobes, brain and cardiac areas are the best sites for determining He presence at highest concentrations. Therefore, on the base of this study, the lung, brain and blood samples were submitted for toxicological analysis in our case. Toxicological analyses were performed also on the rag (only volatile compounds) collected during site inspection and/or autopsy.

$\mathrm{EC}$ was detected in all analysed samples and on the rag (Table 1). Peripheral blood concentrations $(0.165 \mathrm{~g} / \mathrm{L})$ were slightly different from central blood concentration $(0.203 \mathrm{~g} / \mathrm{L})$ collected during autopsy; however, the difference was not significant, since differences in concentrations between peripheral and central blood are very common in post-mortem toxicological analysis and may arise from different factors, such as post-mortem diffusion from adjacent tissues. The lung and brain samples showed EC concentration of 19 and $25 \mathrm{mg} / \mathrm{kg}$, respectively. EC in the vitreous humour showed sensitively lower respect to blood $(0.018$ vs $0.203 \mathrm{~g} / \mathrm{L})$. Important differences in EC concentrations between the vitreous humour and other tissues were also observed according to Broussard et al. (Broussard et al. 2000) reporting a concentration of 0.012 $\mathrm{g} / \mathrm{L}$ in the vitreous humour vs $0.423 \mathrm{~g} / \mathrm{L}$ in the blood. This could be related to an unfavourable partition equilibrium in this district or to physical barriers that prevent gas diffusion. Unfortunately, literature on EC fatal exposures is scarce, and this interpretation of toxicological results is supported exclusively by the case reported by Broussard et al. Loss of ethyl chloride from collected samples was prevented by using tight-seal headspace vials; in fact, no important differences were observed between the results of blood collected at the crime scene $(0.165 \mathrm{~g} / \mathrm{L})$ and at the autopsy $(0.156 \mathrm{~g} / \mathrm{L})$ also because autopsy was promptly performed during the following day. In fact, in case of inhalant intoxication, it remains of utmost importance to safely collect and store the sampled material both during crime scene investigation and autopsy.

The search for other toxicants or volatiles in blood was negative, except for small quantities of ethanol $(0.2 \mathrm{~g} / \mathrm{L})$, which hardly could contribute to the cause of death; it may even have been a consequence of early decomposition.

In consideration of (1) absence of any signs of trauma; (2) toxicological findings that confirm an exposure to ethyl chloride, as suggested by crime scene investigation; (3) negative for other toxicants such as drugs of abuse and pharmaceutical drugs; (4) no suicide notes left, death was attributed to a recreational overexposure to EC.

\section{Conclusions}

The death scene investigation immediately suggested to examine ethyl chloride's role in causing the death, confirming the importance of a correct and comprehensive crime scene investigation (Fais et al. 2017). Considering the analysis of the crime scene, death seemed to occur accidentally and related to recreational abuse instead of a voluntary suicide or a homicide. Moreover, the retrieved empty cans in the trash basket strongly suggested a routine perpetration of EC inhalation. Indeed, the class of the inhalants is reported to be abused for recreational purposes by young male adults, and a review of cases has been proposed by Senussi and colleagues (Senussi and Chalise 2015).

This case reminds the importance of a comprehensive investigation on the death scene, bearing in mind toxicological issues. A proper toxicological sampling and collection both on the crime scene and at the autopsy is mandatory especially in cases of fatal volatile intoxications in order to avoid volatile dispersion. The analysis of volatile compounds in biological matrices, in fact, usually faces some peculiar aspects to be taken in consideration such as the stability in biological specimens, proper sample conservation and redistribution issues in different body districts. In the reported case, samples were collected formerly

Table 1 Toxicological findings of ethyl chloride in different tissues and on the rag

\begin{tabular}{llllllll}
\hline & $\begin{array}{l}\text { Peripheral blood } \\
\text { from CSI (g/L) }\end{array}$ & $\begin{array}{l}\text { VH from } \\
\text { CSI (g/L) }\end{array}$ & $\begin{array}{l}\text { Peripheral blood } \\
\text { from autopsy }(\mathrm{g} / \mathrm{L})\end{array}$ & $\begin{array}{l}\text { Central blood from } \\
\text { autopsy }(\mathrm{g} / \mathrm{L})\end{array}$ & Lung $(\mathrm{mg} / \mathrm{kg})$ & Brain (mg/kg) & Rag (qualitative) \\
\hline Ethyl chloride & 0.156 & 0.018 & 0.165 & 0.203 & 19 & 25 & Positive \\
Ethanol & 0.2 & - & 0.2 & 0.2 & - & - & - \\
Drugs of abuse & - & None & - & None & - & - & - \\
Pharmaceutical drugs & - & None & - & None & - & - \\
\hline
\end{tabular}


on the crime scene, avoiding further time delays, and then at the autopsy, which was performed as soon as possible. Samples were then kept in tight seal vials refrigerated until analysis. Quali-quantitative toxicological analyses seemed mandatory also on non-biological samples retrieved along the death scene investigation. Moreover, also, other psychoactive substances should be investigated to avoid misinterpretation of the real cause of death. In the reported case, EC blood concentration $(0.203 \mathrm{~g} / \mathrm{L})$ was suitable to produce central nervous system depression, which has been reported to be as low as $0.106 \mathrm{~g} / \mathrm{L}$ (Clayton and Clayton 1993-1994). Certainly, the toxicological interpretation of these findings is hampered by the small number of reported cases in the literature. More in general, the lack of data on rare causes of death limit the forensic toxicologist to state with absolute certainty on this point. However, a proper integration of pathological and circumstantial findings may help on the reconstruction of the fatal event as demonstrated from the reported case.

\section{Abbreviations}

EC: Ethyl chloride; GC-MS : Gas chromatography coupled to mass spectrometry; HS-GC-FID: Headspace gas chromatography coupled to flame ionization detector; LC-MS/MS: Liquid chromatography coupled to tandem mass spectrometry

\section{Acknowledgements}

None

\section{Authors' contributions}

JP carried out the experiments. PF and JP wrote the manuscript with the support and suggestion by GC. GV and MM helped supervise the project. PF conceived the original idea. All authors discussed the results and contributed to the final manuscript. All authors read and approved the final manuscript.

\section{Funding}

None

\section{Availability of data and materials \\ None}

Ethics approval and consent to participate

Not need

\section{Consent for publication}

Consent from each author

\section{Competing interests}

The authors declare that they have no competing interests.

\section{Author details}

${ }^{1}$ Forensic Toxicology Division, Department of Health Sciences, University of Florence, Largo Brambilla 3, 50134 Florence, Italy. ${ }^{2}$ Department of Medical and Surgical Sciences, DIMEC, University of Bologna, 40126 Bologna, Italy.

${ }^{3}$ Legal Medicine and Toxicology, University-Hospital of Padova, Via Falloppio, 50, 35121 Padova, Italy.

Received: 3 April 2019 Accepted: 29 May 2019

Published online: 11 June 2019

\section{References}

Al-Ajmi AM, Morad MA, Cooper PE, Hassino LH (2018) Reversible ethyl chloride neurotoxicity: a case report. J Can Sci Neurol 45:119

Baselt RC (2014) Disposition of toxic drugs and chemicals in man, 10th edn. Biomedical Publications, Seal Beach, pp 799-800
Bertol E, Di Milia MG, Fioravanti A, Mari F, Palumbo D, Pascali JP, Vaiano F (2018) Proactive drugs in DFSA cases: toxicological findings in an eight-years study. Forensic Sci Int 291:207-215

Broussard LA, Broussard AK, Pittman TS, Lirette DK (2000) Death due to inhalation of ethyl chloride. J Forensic Sci 45:223-225

Clayton GD, Clayton FE (eds) (1993-1994) Patty's industrial hygiene and toxicology. Volumes 2A, 2B, 2C, 2D, 2E, 2F: Toxicology, 4th edn. Wiley, New York, p 4084

Cruz SL (2011) The latest evidence in the neuroscience of solvent misuse: an article written for service providers. Subst Use Misuse 46:62-67

Da Broi U, Colatutto A, Sala P, Desinan L (2015) Medico legal investigations into sudden sniffing deaths linked with trichloroethylene. J Forensic Legal Med 34:81-87

Ethyl Chloride, or EC, is new off-the-shelf high - YouTube. n.d. https://www. youtube.com/watch?v=I1Z9RKDOzOk, Accessed 12 Feb 2019

Fais P, Pigaiani N, Cecchetto G, Montisci M, Gottardo R, Viel G, Pascali JP, Tagliaro F (2017) "Tampering to death": a fatal codeine intoxication due to a homemade purification of a medical formulation. J Forensic Sci 62:1671-1673

Fedtke N, Certa H, Ebert R, Wiegand HJ (1994a) Species differences in the biotransformation of ethyl chloride. I. Cytochrome P450-dependent metabolism. Arch Toxicol 68:158-166

Fedtke N, Certa H, Ebert R, Wiegand HJ (1994b) Species differences in the biotransformation of ethyl chloride. II. GSH-dependent metabolism. Arch Toxicol 68:217-223

IARC, Chloroethane monograph, (1991) https://monographs.iarc.fr/ENG/ Monographs/vol71/mono71-81.pdf, Accessed 17th Apr 2019

Kim YH, An YJ, Jo S, Lee SH, Lee SJ, Choi SJ, Lee K (2018) Comparison of volatile organic compounds between cigarette smoke condensate (CSC) and extract (CSE) samples. Environ Health Toxicol 33:e2018012-e2018010

Kramp KH, Salih M, Thomeer E, Gardien M (2018) Cardiac arrest by inhalation of deodorant spray. BMJ Case Rep 15. https://doi.org/10.1136/bcr-2018-224345

Kuthiah N, Er C (2019) "High" on muscle spray - ethyl chloride abuse. Ann Acad Med 48:69-71

McCardie WJ (1905) Remarks on the position of and mortality from ethyl chloride as a general anaesthetic. BMJ 2359:616-618

Murray Lawson JI (1965) Ethyl chloride. Brit J Anaesth 37:667-669

Romolo FS, di Luca NM, Ciallella C, Bottoni E, Fiore PA, Cappelletti S, Giuliani N, Augsburger M, Varlet V (2017) Volatile lipophilic substances management in case of fatal sniffing. J Forensic Legal Med 52:35-39

Senussi MH, Chalise S (2015) Acute reversible neurologic deficits due to ethyl chloride sniffing: a case report and review of literature. Am J Ther 22:e40-e42

Tomei Torres FA, Keith S (2016) Toxicological profile for chloroethane, addendum to the toxicological profile for chloroethane, Agency for Toxic Substances and Disease Registry Division of Toxicology and Human Health Sciences Atlanta, Georgia. http://www.atsdr.cdc.gov/toxprofiles/chloroethane_ addendum.pdf

Torfaen County Borough Council Planning \& Public Protection, Code of practice Body Piercing, n.d. https://www.torfaen.gov.uk/en/Related-Documents/ Licensing/Body-Piercing-Code-of-Practice.pdf, Accessed 16th Apr 2019

Varlet V, Iwersen-Bergmann S, Alexandre M, Cordes O, Wunder C, Holz F, Andresen-Streichert H, Bevalot F, Dumestre-Toulet V, Malbranque S, Fracasso T, Grabherr S (2019) Helium poisoning: new procedure for sampling and analysis. Int J Legal Med Feb 7 https://link.springer.com/article/10. 1007\%2Fs00414-019-02014-3

Winek CL, Wahba WW, Winek CL Jr, Balzer TW (2001) Drug and chemical bloodlevel data 2001. Forensic Sci Int 122:107-123

Yacoub I, Robinson CA, Simmons GT, Hall M (1993) Death attributed to ethyl chloride. J Anal Toxicol 17:384-385

Youths warned off sniffing 'deadly' new legal high Ethyl Chloride - n.d. https://www.financialexpress.com/lifestyle/health/youths-warned-offsniffing-deadly-new-legal-high-ethyl-chloride/138600/, Accessed 12 Feb 2019

Zhang L, Wu P, Jin Q, Hu Z, Wang J (2018) Multi-residue analysis of sedative drugs in human plasma by ultra-high performance liquid chromatography tandem mass spectrometry. J Chromatogr B 1072:305-314

\section{Publisher's Note}

Springer Nature remains neutral with regard to jurisdictional claims in published maps and institutional affiliations. 